\section{Dilated superior vena cava in fetal echocardiographic three- vessel view: what lies ahead?}

A 38-year-old woman, 37+3 weeker was incidentally detected to have fetal cardiomegaly during 36 weeks ultrasound and referred for fetal echocardiogram. Antenatal history and anomaly scan were normal. Fetal echocardiogram showed heart rate of $153 / \mathrm{min}$, sinus rhythm, situs solitus, levocardia, dilated right atrium and ventricle with venoatrial, atrioventricular and ventriculoarterial concordances. All cardiac valves were normal; cardiac crux was intact with separate mitral and tricuspid annuli (figure $1 \mathrm{~A}-\mathrm{C}$ and online supplementary video 1). Mild tricuspid regurgitation with peak velocity of $1.77 \mathrm{~m} / \mathrm{s}$ was noted. There was no evidence of Ebstein's anomaly. Interventricular septum was intact. Pulmonary veins were seen entering left atrium (LA) without a retrocardiac chamber. Both aortic and ductal arches were adequate but with significant flow reversal visualised in descending aorta. Threevessel view showed dilated right superior vena cava (SVC) with normal spatial arrangement and sizes of aorta and pulmonary artery. Patent foramen ovale and patent ductus arteriosus were shunting normally. Inferior vena cava (IVC), hepatic and portal veins were normal. Significant hepatomegaly was seen without any evidence of hydrops.

\section{QUESTION}

As per the available echocardiographic data, what is the most likely diagnosis for fetal heart failure?

A. Idiopathic dilatation of SVC?

B. Supracardiac total anomalous pulmonary venous connection?

C. Fetal vein of Galen malformation?

D. Fetal anaemia?

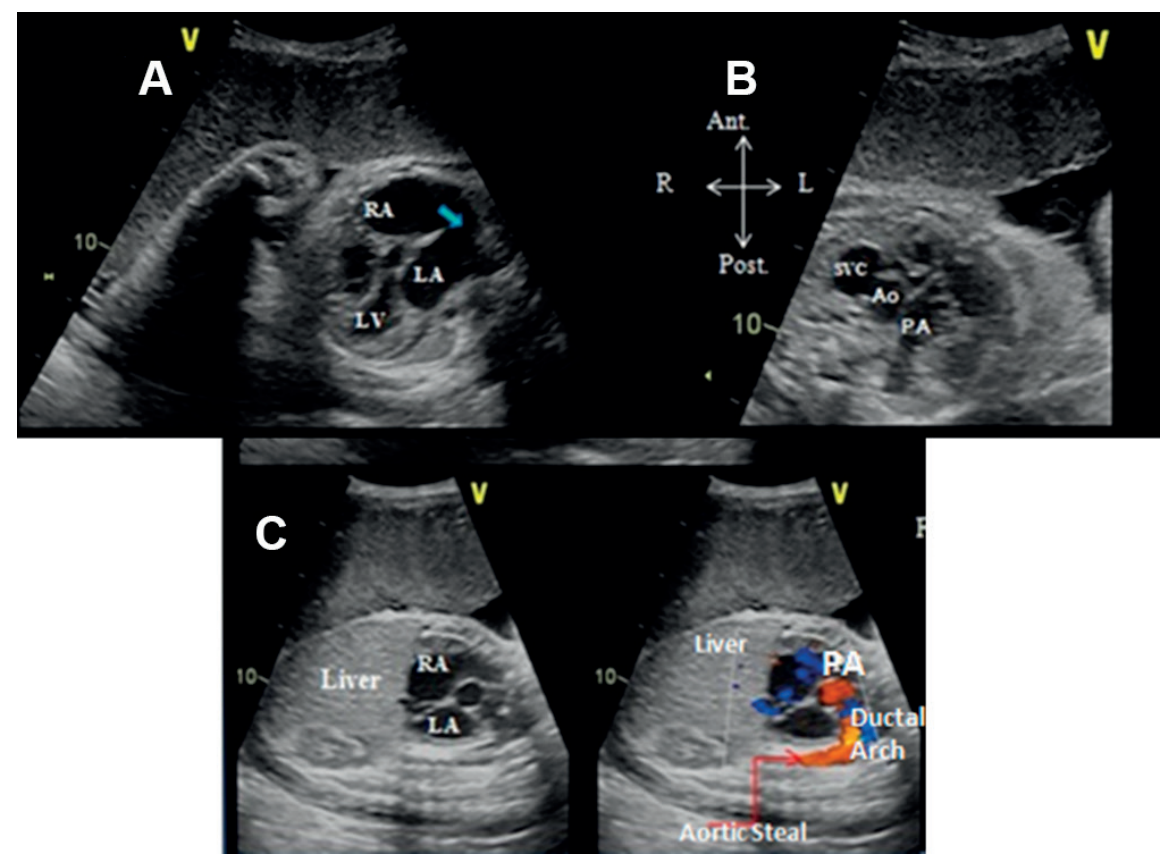

Figure 1 (A) Fetal echocardiogram showing atrioventricular concordance with right atrium (RA) connected to morphological right ventricle and left atrium (LA) connected to morphological left ventricle (LV). Blue arrow depicts a large foramen ovale shunting from RA to LA. There is no retrocardiac chamber behind LA. (B) Three-vessel view in fetal echocardiogram showing normal right to left arrangement of superior vena cava (SVC), aorta (Ao) and pulmonary artery (PA). Interestingly, SVC is bigger than its neighbours which is against the norm. (C) Fetal short-axis echocardiographic view showing situs solitus with normal arrangement of RA and LA. RA is draining into right ventricle which is draining through PA into the ductal arch. However, significant aortic run-off is noted in aorta. 


\section{ANSWER: C}

Cardiomegaly with dilated SVC (online supplementary video 2) and normal IVC usually suggests supracardiac total anomalous pulmonary venous connection. However, as pulmonary veins were draining into LA, option (B) is wrong. Fetal anaemia, option (D) was excluded by demonstrating normal peak systolic flow in middle cerebral artery.

In this scenario with differential flow patterns in SVC and IVC, there are two differentials. Either idiopathic dilatation (IDSVC) (option A) or increased systemic venous return to SVC through arteriovenous malformation. We interrogated the catchment area of SVC, namely, brain and upper extremities. It was difficult due to term gestation and lateral lie. But by increasing 2D sector width and electronically tilting the transducer towards fetal skull, a giant anechoic space with torrential vascular flow (online

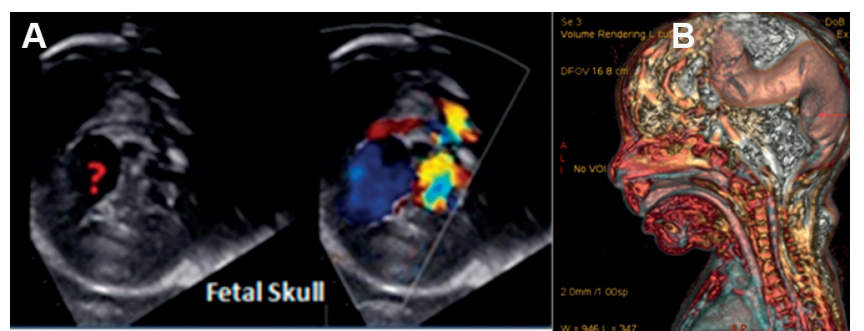

Figure 2 (A) M5 Hz echo transducer focussed now on the fetal skull showing large echolucent space (marked with red question mark) and concomitant colour Doppler showing torrential vascular flow into it. (B) Neonatal 3D cranial MR angiogram confirming the giant vein of Galen malformation. supplementary video 3) was seen. Thus, option (C), that is, fetal vein of Galen malformation is the correct answer (figure $2 \mathrm{~A}$ ). Neonatal cranial MRI (figure 2B) confirmed it.

Literature also reports a rare scenario of IDSVC where focal dilatation of only SVC, in the absence of increased systemic venous return or increased filling pressure, diagnosed incidentally in X-ray. But it was excluded here by typical intracranial imaging.

\section{Maitri Chaudhuri, Subashchandra V, S S lyengar}

Department of Cardiology, Manipal Hospital, Bangalore, Karnataka, India

Correspondence to Professor S S lyengar, Department of Cardiology, Manipal Hospital, Bangalore 560017, Karnataka, India; ssiyengar1945@gmail.com

Contributors $M C$ was in charge of the patient. All the authors were involved in the discussion and preparation of the manuscript.

Funding This research received no specific grant from any funding agency in the public, commercial or not-for-profit sectors.

Competing interests None declared.

Patient consent Guardian consent obtained.

Provenance and peer review Not commissioned; externally peer reviewed.

(c) Article author(s) (or their employer(s) unless otherwise stated in the text of the article) 2018. All rights reserved. No commercial use is permitted unless otherwise expressly granted.

- Additional material is published online only. To view please visit the journal online (http://dx.doi.org/10.1136/heartasia-2018-010998).

Check for updates

To cite Chaudhuri M, V S, lyengar SS. Heart Asia 2018;0:e010998.

Heart Asia 2018;0:e010998. doi:10.1136/heartasia-2018-010998 